\title{
The Sustainability Issue at the Time of the Epidemic. The Abnormal Cycle of Finance
}

\author{
Dott Giovanni Antonio Cossiga \\ Presidente Collegio sindaci, Policlinico Umberto 1, Università Sapienza-ROMA, Roma, Italy \\ Email: g.cossiga@alice.it
}

How to cite this paper: Cossiga, D. G. A. (2020). The Sustainability Issue at the Time of the Epidemic. The Abnormal Cycle of Finance. Theoretical Economics Letters, 10, 946-977.

https://doi.org/10.4236/tel.2020.104056

Received: July 12, 2020

Accepted: August 28, 2020

Published: August 31, 2020

Copyright $\odot 2020$ by author(s) and Scientific Research Publishing Inc. This work is licensed under the Creative Commons Attribution International License (CC BY 4.0).

http://creativecommons.org/licenses/by/4.0/

(c) (i) Open Access

\begin{abstract}
The sustainability principle explains the economic situation and its alterations according to the basic view of continuity, in the view of life preservation for future generations. From this perspective, the troubles affecting the economy, including those caused by the COVID 19, must be interpreted under the sign of the instability of systems, while following the natural tendency to recover the compatibility with nature. Even the cycle of the economy is accompanied by the recession and involution of the economy, which are to be interpreted as natural tools for the return to development equilibrium. According to this approach, the financial crises of the 2000s are symptoms of the serious gap separating us from the balanced development and from the irrevocable obligation to systems stability. On this issue, we will try to understand whether the possibility that the financial tsunami caused by financial crises is the result of an ambiguous and abnormal secondary financial cycle, which overlaps with the economic cycle. Therefore, it doesn't seem unlikely that the breakdown imposed by the pandemic on the global economy could have the effect of blocking, but only temporarily, the development of the secondary financial cycle. It's therefore not surprising at all that a few months after the outbreak of the pandemic, the financial market, after the fall of last March, is now raising again (see the US Stock exchanges) despite the collapsed employment. The hypothesis we propose is that it's the serious phenomenon of the unusual concentration of wealth and income to the detriment of the rest of the community, the improper engine of the adverse financial cycle. It is Adverse because it falls on the economy and once again is inflicting a heavy damage on the weaker part of the community. It should be noted that also this fearful wave in the financial market would be caused by a natural reaction. The natural goal of the financial cycle would be, indeed, to periodically demolish wealth, through the collapse of stock exchange values and related assets. At the same time, the increasing unemployment and corporate crises would be contrasted with Keynesian policies, which can be seen
\end{abstract}


as means for a more equitable distribution of wealth and income. However, the natural goal is partially disregarded for the enormous low-cost liquidity available on the market, and this will finally allow the financial part to prevail over the market. What to do, then? It's necessary and advisable to promote a greater equity in the distribution of income and wealth.

\section{Keywords}

Deflation, Sustainability, Abnormal Cycle, Development Equilibrium, Corrective Mechanism

\section{Introduction}

The sustainability principle interprets the economic situation and its alterations according to the continuity basic perspective. The presence of life and humankind on the planet is justified by the fundamental principle of safeguarding life for future generations. From this point of view, even the terrible plagues of the past as also the present SARS-CoV-2 pandemic are inevitable and fearsome passages, but anyway humanity looks far ahead. Because its long-way destiny is to explore the physical world all around. A goal that focuses on the research and creativity of the human being, in the assumption that science is bringing us closer to know and understand the nature and, therefore, to live according to compatibility with the evolution of the planet that hosts us.

So, science is the channel through which Mother nature speaks to humanity. Therefore, there is no doubt that to achieve or maintain this compatibility between nature and mankind a mutual exchange of messages is required. It is an exchange of messages that would somehow warn human beings when and if the development path was to be in line with-or to deviate from-the balanced relationship with the evolution of natural events.

Only in this way we can understand the long march of humanity down to us, despite the fearful natural cataclysms, the great epidemics as well as the effects of the human character still selfish and violent. Humankind is always able to rise again because its ultimate destiny must be achieved: the knowledge of nature all around. Therefore, even the economic events must follow the knowledge evolution, and this finally means to adapt the behavior of human beings to the path indicated by the natural evolution.

From this point of view, it is obvious that this adaptation is progressing and evolving precisely on the basis of the scientific advancements. And this is just to say that the path of economic affairs can be, as often happens, divergent from the natural balance between mankind and nature. Because only with a greater knowledge of the world around us, we would achieve a balanced and coordinated adaptation to nature.

Following this approach, it seems clear that the appearance of SARS-CoV-2 
epidemic and the current lack of valid devices to fight it, pointed out a backwardness of science in the fight against viruses and contagious diseases. Therefore, if the appearance of this new pandemic will mark the start of an emphasis in the field of research, involving not only the pharmaceutical industries but altogether technology, computer science, fine mechanics, chemistry, in the search for new treatments, it will mark then a positive point on the path of balance with nature.

Therefore, we should realize that we are often on a path of unbalanced development. And that this imbalance is generally reported to us by the poor growth of the economy, but also by its distorted and doped development. In fact, if the path of the economy is balanced it becomes inevitable that the development potential would be extended to the maximum. For the obvious reason that the economic progress is also and above all a greater and increasing processing capacity in science and creativity, which is the common goal of our presence on the planet and of our survival. If that is the case, in a balanced and compatible economy we should experience a gradual but constant development over time. So, a development along a straight line and with an inclination (development pace) depends on the potential and historical circumstances.

From this consideration it appears that not only the world of economics is traveling on an unbalanced path, but also that the anomalies surrounding our path in everyday life are all somewhat linked to the deviation from the path of compatibility with the environment. So, first, it's the twisted and serpentine trend of the economy that overlaps and replaces the linear and constant trend characterizing the balanced development of the economy.

It follows that all the anxieties troubling families and companies, due to an economic situation becoming negative over time and difficult to control, are therefore deriving from anomalies in the economy management. The strategies used to bring the economic system back on the balanced path, therefore, move on the assumption that the cyclical evolution of the economy is a basic, unavoidable character. And therefore, we can only try to control them, in the attempt to keep the economy within a relatively quiet area. With the result that in this way we fight the symptom of malaise, that is the cyclical decline of economic growth, and not the real disease, that is the instability of the systems in their relationship with the nature around us.

In this way, however, the great accused would be the nominal price movement, which may indicate an alteration in the availability of raw materials, especially oil. But it can also be an expression of a nominal price run, unrelated to the motion of the real economy but just an image of the imbalance within economic systems. In this case, the nominal prices do not go according to the real economy but follow instead an acceleration or deceleration which are a sort of mirror, just an image of the economy, but actually are not part of it. That is, they are messages created by the instability and imbalance of the economy; they are tools for a direct and immediate knowledge about the economic affairs, which everybody can interpret. Because we all immediately understand the ultimate 
meaning: we need to correct the course of the economy.

On the other hand, how to explain that our neighbor, the common man, have a synthetic and somewhat abstract perception about the conditions of the economy and the market. Of course, every perception is based on the summary information provided by prices, rapidly rising (inflation) or tending to decrease (deflation). But not only that. If we ask the common man about the state of the economy, exactly as we do with the reliable indicators on the market trend, it could happen that he will give us some solution, very concise indeed, to solve the problem of uncertainty in the economic sphere.

All this should make us reflect about the relationship that exists and is maintained between the nature around us and the humanity, in particular the communities that we must consider as a real arrival point of the unexpressed or direct communication coming from the environment. Nor could it be otherwise, because humankind's goal is to preserve life over time, to continue the human history through future generations. So, there must be a parallel purpose between nature and humanity: both aim to keep the planet in a position to always support the life.

From this point of view, we should believe that even a pandemic like this now experienced worldwide must be considered as a harsh reaction from nature, caused by errors and failings in the environmental relationship. Errors and failings caused also by the way the research and science are conducted, when in the private sector they focus and investigate sometimes according to schemes following a commercial and business logic. While the public part of the research sector-as demonstrated by the current experience-seems to have underestimated the importance of measures to be taken against the rise and spread of viruses.

\section{Method}

\subsection{Pandemic or Deflating Bubble: Which One Is the Cause of the Announced Recession?}

From the point of view of the sustainability economy, the creaks of a potential global recession for a long time were warning about the growth course disruption within the major economies. Indeed, we should not forget that an insertion of inappropriate scenarios has been created on a global level as well as inside large countries and continents.

In fact, we should understand that the development anomalies, for a long time so evident in the economic scenario, are now showing the irrevocable tendency to recession with the result of an increasing precariousness of the economy. As said, the conjuncture cycle is essentially a remedy, not a malaise, to reduce the instability inside economic systems. Like any remedy, it must be paid, so the deep recession becomes a dangerous trouble not only economically but above all socially (Cossiga, May 2019).

The problem is to follow a balanced growth path compatible with the evolution of surrounding nature, which would allow a linear and constant growth. 
Excluding, therefore, the bulky presence of the economic cycle, which is a natural remedy to bring systems back to a balanced compatibility. Hence, the hard and difficult work of the economy at a global level is testified primarily by the presence in all continents of the pace imposed by the conjuncture cycle.

In addition, a significant factor to express the economy's difficulty is to be found in the spasmodic search of markets and finance for new and greater liquidity. And all this is related to the willingness of the Central banks to meet that pressing request, to help the markets in the stagnation phase, eventually to then accelerate the recovery hopefully in the near future. Now it is obvious that the demand for new liquidity would imply an expansion of finance beyond the limits allowed by its function of natural support to the real economy. It is clear that once is overcome this relationship of opportune connection with the real economy, we are launching, while finance is getting bigger and bigger with the liquidity available, a financial bubble that sooner or later will have to burst, with enormous damage for the real economy (Krugman, 2009).

The most obvious symptom of this preparing bubble is certainly the disparity in the distribution of income and wealth, which is now a constant in all large countries, especially the USA and China. The bubble grows in relation to the availability of cheap liquidity on the market. A situation which, on the one hand, is a symptom of degradation due to the appearance of price deflation, complementary to the giant degeneration of finance. On the other hand, it is the condition that makes possible the fall of interest rates to levels close to zero and the abundance of liquidity to satisfy the market.

Central banks respond to deflation on the market with the usual monetary policy: decreasing cost of money and increasing liquidity. These could seem appropriate measures for companies, in order to avoid a cascade disintegration of their production potential. But the liquidity flowing on the market goes only partially towards the real economy, while a big amount goes towards the finance. For the simple reason that large capital can offer to the credit market, the strength of its great wealth. But I would say above all because the Stock exchange, which is the meeting place between finance and the real economy, feeds the growth of the stock market values of large and medium-sized enterprises, so pushing them towards an abnormal dimension anyway unrelated to the real

${ }^{1}$ Part of the explanation for the remarkable price behavior between 1990 and 2000 may have to do with the unusual behavior of corporations' profits as reflected in their earnings reports. Many observers remarked then that earnings growth in the five-year period ending in 1997 was extraordinary: real S\&P Composite earnings more than doubled over this interval, and such a rapid five-year growth of real earnings had not occurred for nearly half a century. But 1992 marked the end of a recession during which earnings were temporarily depressed. Similar increases in earnings growth following periods of depressed earnings from recession or depression have happened before. In fact, there was more than a quadrupling of real earnings from 1921 to 1926 as the economy emerged from the severe recession of 1921 into the prosperous Roaring Twenties. Real earnings doubled during the five-year periods following the depression of the 1890s, the Great Depression of the 1930 s, and World War II. It was tempting for observers in 2000, at the peak of the market, to extrapolate this earnings growth and to believe that some fundamental changes in the economy had produced a new higher growth trend in earnings (Shiller, 2015). 
values. ${ }^{1}$ (Shiller, 2015)

The considerations of the Central banks on the transmission of monetary policy (see: note 4) are an undoubted signal that the abundant liquidity, which is injected on the market, only partially is reaching the companies. A condition that worsens when the serious recession, such as the one we are experiencing with the coronavirus, increases the risks for banks, due to the increase in insolvencies, ongoing or expected. On the other hand, the volatility of spreads, in the case of the Europe of 27 is also an implicit brake on corporate credit, due to the different cost of money between the countries of the euro area (Table 1). A mechanism will further reduce the flow of corporate credit, despite the great availability of liquidity that the Central banks inject into the economic system. Then liquidity, although enormous compared to the needs of the real economy, takes the way of the financial markets. Thus, in this way may be fed a bubble in the values of the stock exchange and other assets, which are however connected to the financial market fate. ${ }^{2}$

It should be noted that the wealth effect produced by the rising financial markets is a fire that only feeds some portions, even limited anyway, of the real economy, which instead remains essentially aloof regarding this effervescence. As demonstrated by the tendency to deflation during the rise and fermentation of the speculative bubble (with a rising curve of nominal price only at the top of the speculative run) as well as the moderate or basic growth of the economy, experienced during the first decade of the 2000s (Figure 1).

The values of the financial market are essentially growing, while the expressions

Table 1. Spread of European government bonds on April 10, 2020.

\begin{tabular}{ccccc}
\hline Nation & Name & Price & Var \% & Previous Spread \\
\hline Austria & Spread Austria-Bund 10Y & 58.4 & $+7.16 \%$ & 54.5 \\
Belgium & Spread Belgium-Bund 10Y & 52.4 & $+0.19 \%$ & 52.3 \\
Denmark & Spread Denmark-Bund 10Y & 31.2 & $+4 \%$ & 30 \\
Finland & Spread Finland-Bund 10Y & 49.7 & $+12.95 \%$ & 44 \\
France & Spread OAT-Bund 10Y & 45 & $+0.45 \%$ & 44.8 \\
Ireland & Spread Ireland-Bund 10Y & 63.7 & $+7.6 \%$ & 59.2 \\
Italy & Spread BTP-Bund 10Y & 196.7 & $+1.13 \%$ & 194.5 \\
Netherlands & Spread Netherlands-Bund 10Y & 26.1 & $-2.61 \%$ & 26.8 \\
Portugal & Spread Portug-Bund 10Y & 129.9 & $+1.72 \%$ & 127.7 \\
Czech Rep & Spread Czeck Rep -Bund 10Y & 187.2 & $+0.65 \%$ & 186 \\
Slovenia & Spread Slovenia-Bund 10Y & 117.6 & $-0.51 \%$ & 118.2 \\
Spain & Spread Bonos-Bund 10Y & 129.3 & $+15.34 \%$ & 112.1 \\
Hungary & Spread Hungary-Bund 10Y & 309.9 & $+0.39 \%$ & 308.7 \\
\hline
\end{tabular}

Source: Newspaper "Sole 24ore" April 10, 2010.

${ }^{2}$ The spread is the yield differential between two indicators, one for reference (benchmark) and one for measurement, of the same type and of equal duration. In the case, it is the differential between the European government bonds and the German Bund. 

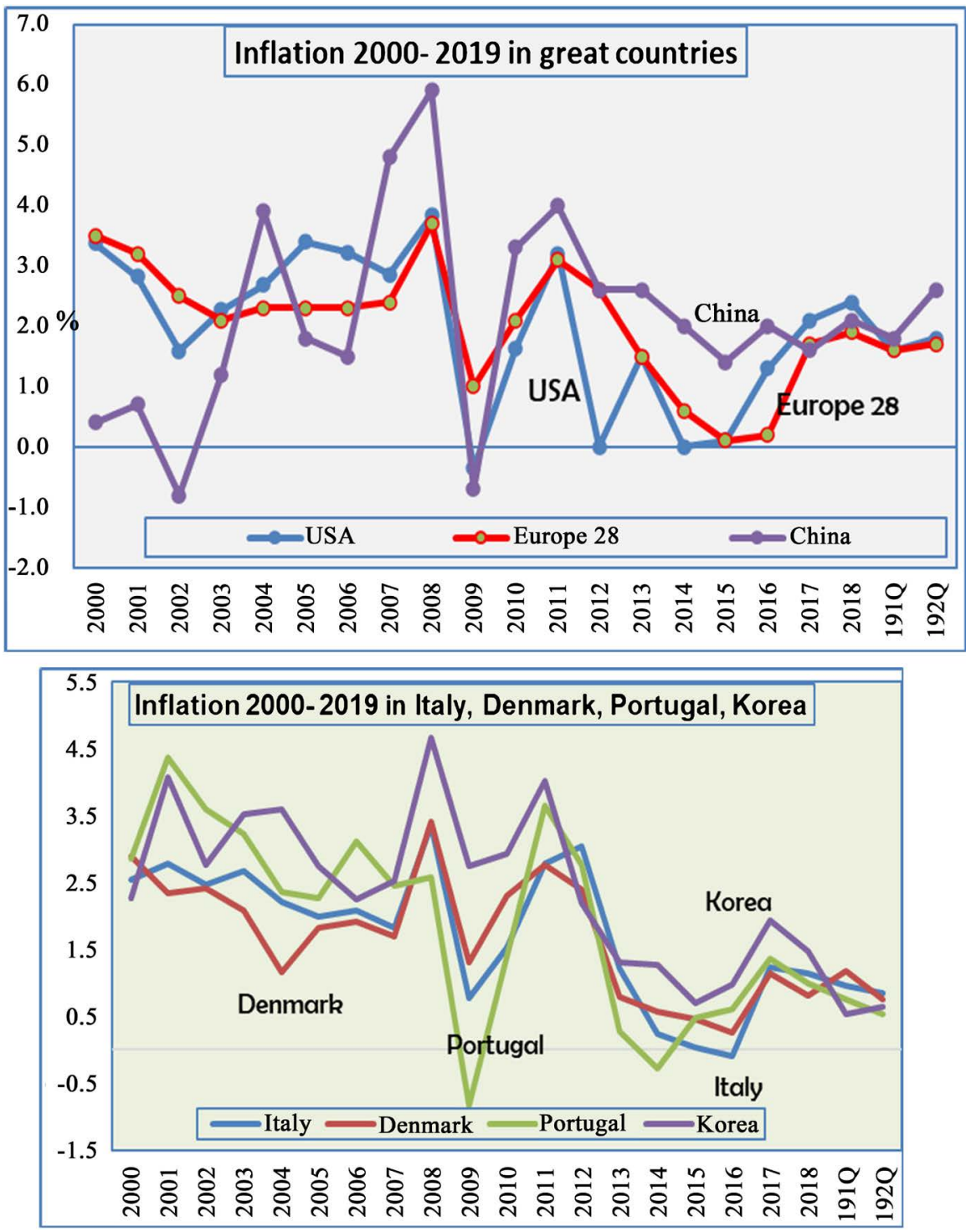

Source-Elaboration on OECD data.

Figure 1. Inflation trend in great countries from 2000 to 2019.

of the real economy remain quiet, largely unaffected by the speculative excitement. The inflated values of listed companies, unrelated to the underlying actual economic value of the production activity, is a market manipulation which is made possible by the abnormal distribution of income and wealth at the level of large countries. The distorted income distribution is a leaven which in turn increases the income and wealth of the privileged part of the community. Now, all this will bring precariousness, and not only for the resulting evident social damage for the dignity of individuals and families. But furthermore because, unfortunately, it hides a speculative mechanism that must sooner or later deflagrate, so inflicting serious damage on the economy although the production activity has been little, or even nothing involved in the speculative excitement (Cossiga, April 2018). 
It is not surprising that the breaking of the financial bubble moves in accordance with the primary objective: to put the economy in step with the balance and compatibility. The goal of the bubble disintegration phase should be, among other things, to contain and reduce the upward divergence of income and wealth, thus making possible a more balanced sharing of the common welfare.

And in fact, the gradual disintegration of the financial bubble means nothing less than the shaping and reduction of wealth of the privileged part of society, which therefore shouldn't have the possibility to count on support forms to reduce this reshaping action. A theoretical hypothesis partially not confirmed. Why?

In fact, there is a sensational drop in the value of securities and assets, which obviously depress the wealth at the top of social ladder. Nevertheless, this reshaping works during the most critical phase of the financial bubble breaking. It is then a result that seems temporary, as demonstrated by the scale of values in the income distribution after years since the bubble burst in 2008-2010. ${ }^{3}$ Essentially, referring to 2016, the income and wealth distribution, far from showing more balance, has become increasingly unequal.

Basically, we can say that the storm of the recent financial crisis has led to an arrangement at the top with winners and losers, according to the ability demonstrated in mastering the financial crisis, and especially in managing the post-crisis period. A zero or negative balance therefore appears to be only the result of a traumatic event, what is in fact the financial crisis. An event that must be considered as a defense mechanism of the economic system, in search of a balance not only at the economic level but also at the social level.

In the sense that the speculative crisis should be considered a sort of a way out of the system trying to find again the path to the compatibility and balance with nature. As saying that the exit of the economic growth process from the path of a balanced relationship with nature, over time should be corrected in order to return soon to the equilibrium. This irrevocable need to rebalance the altered systems can lead to a speculative crisis if the gap of the economic system from the equilibrium path is too wide.

In other words, the financial crisis is the last resort tool for the correction of the altered economic system. However, we are finding that the correction through the speculative paradigm may not fully work in the difficult task of achieving a greater equity in the income and wealth distribution within a community.

The great liquidity that is provided to the market at a low cost, in fact, has the primary objective to favor credit to businesses, which during the crisis are suffering from a sudden and unexpected lack of liquidity. Banks in turn are stressed, facing the possibility that the budget risk would increase with the growing difficulties of the economy. A condition ends up damaging the real

${ }^{3}$ The ten-year average smooths out such events as the temporary burst of earnings during World War I, the temporary decline in earnings during World War II, and the frequent boosts and declines that we see due to the business cycle. Note again that there was an enormous spike after 1997, when the ratio rose until it hit 47.2 intraday on March 24, 2000. Price-earnings ratios by this measure had never been so high. The closest parallel was September 1929, when the ratio hit 32.6 (Shiller, 2015). 
economy, also because this uncertain situation can favor those financial companies that speculate on the market. Thus, a sort of redistribution of wealth can be started at the top of social scale, thus, essentially nullifying the work of natural correction in the wealth distribution, which then remains the goal of the speculation-crisis paradigm.

\subsection{The Speculation-Crisis Paradigm and the Financial Markets}

There is no question about the need for monetary policy measures to relieve the market from the economic troubles. Instead, let us talk about having arrived at the unexpected SARS-CoV 2 epidemic in a condition of overexposed finance and with the economy showing a long and increasing instability. As shown by the trend towards deflation that involved the global economy. In other words, we arrived at the unexpected epidemic appointment with the financial markets that pushed the quotation of the companies, so achieving a cyclically adjusted price-earnings ratio (CAPE) that reached and exceeded the level 47.2 reached in 2000.

Now it should be noted that the overexposure of the financial markets essentially means that the values of the securities become virtual for the share part delimited by the exceeding quotation compared to the value of the company, according to the established methodology.

Let us imagine this bubble that is forming in the markets as a possible subtraction of potential from the economy, which can be reached in a condition of balance and compatibility. In other words, the virtual excess of stock market prices occurs at the expense of the real economy, which in fact remains little involved in the speculation excitement and is showing a constant trend towards price deflation.

It follows that the speculation circuit involves the financial markets and consequently the real estate market, which adapts to the speculative game because the loan credit is guaranteed by a real value and therefore apparently safe. This is a valid guarantee during the formation of the speculative bubble, but however becomes quite uncertain when the financial crisis causes the value collapse and the liquidity destruction. The following financial crisis erupts into the financial markets and into the sectors involved in virtual growth but also the real economy is heavily touched and suffers for the liquidity progressive destruction with the recession wide spreading.

The speculation-crisis paradigm therefore develops by creating a wealth effect with the growth of stock market values, which has little or bad impact on the economy. As demonstrated, moreover, by the trend of labor costs following a weak trend, though partially justified by the deflationary trend of prices. This is to say that even the eventually growing employment curve is unable to mitigate, even slightly, the income inequality during the speculative phase. Indeed, the virtual growth of the financial market, that is not connected to the real values of the market economy, is the tireless engine concentrating the wealth and income at the top of social ladder.

It follows that not only the wealth escalation towards the top can be consi- 
dered a serious anomaly dependent on the economic instability. But that also the sequence of speculative events, which we are observing since the last decade of the past century, is essentially a chain of self-powered events that is destined to be repeated in the future. Events have the natural goal, which revealed to be precarious, to maintain and not increase the wealth and income shift towards the higher social scale. Precarious because at the community level, the financial speculative phase modifies only temporarily the status quo regarding the inequality in income and wealth distribution. Moreover, the speculative crisis phase destroys jobs and makes unemployment wide spreading. As saying that much of the community suffers for a further upward shift of incomes.

The issue of the monetary policy transmission in the economy ${ }^{4}$ therefore, suffers from serious limitations, because despite the creation of large quantities of liquidity on the market, and the near-zero liquidity cost for banks; however the banks can be overwhelmed by the rapid deterioration of the real economy. They are therefore unable to perform their role of liquidity mediators towards the economy, due to the rigidity of the balance sheet and the losses caused by outstanding credits or anyway difficult to collect.

Therefore, the banking channel is hampered by the condition of the economy in recession, which affects the balance sheet and therefore the ability of banks to let flow towards business companies the liquidity made available by Central banks through longer-term refinancing operations.

The lending to companies is therefore an increasing source of risk and the banks, in the absence of government interventions able to protect against risk, reduce the interventions supporting real economy. For this reason, during and especially after the spreading of the financial crisis, the credit is preferably directed towards large companies and financial firms, which have huge resources and important social channels.

In some ways, this behavior of banks, which appears justified because sur-

${ }^{4} 1$ ) Additional longer-term refinancing operations (LTROs) will be conducted, temporarily, to provide immediate liquidity support to the euro area financial system. Although the Governing Council does not see material signs of strains in money markets or liquidity shortages in the banking system, these operations will provide an effective backstop in case of need. They will be carried out through a fixed rate tender procedure with full allotment, with an interest rate that is equal to the average rate on the deposit facility. The LTROs will provide liquidity at favourable terms to bridge the period until the TLTRO III operation in June 2020. ECB Monetary policy decisions. March 12, 2020-A new series of non-targeted pandemic emergency longer-term refinancing operations (PELTROs) will be conducted to support liquidity conditions in the euro area financial system and contribute to preserving the smooth functioning of money markets by providing an effective liquidity backstop. The PELTROs consist of seven additional refinancing operations commencing in May 2020 and maturing in a staggered sequence between July and September 2021 in line with the duration of the collateral easing measures. They will be carried out as fixed rate tender procedures with full allotment, with an interest rate that is 25 basis points below the average rate on the main refinancing operations prevailing over the life of each PELTRO. ECB Monetary policy decisions. April 30, 2020

2) In connection with these plans, the Committee voted unanimously to authorize and direct the Federal Reserve Bank of New York, until instructed otherwise, to execute transactions in the System Open Market Account in accordance with the following domestic policy directive: The Committee also directs the Desk to continue conducting term and overnight repurchase agreement operations to ensure that the supply of reserves remains ample and to support the smooth functioning of short-term U.S. dollar funding markets. In addition, the Committee directs the Desk to conduct overnight reverse repurchase operations (and reverse repurchase operations with maturities of more than one day when necessary to accommodate weekend, holiday, or similar trading conventions) at an offering rate of 0.00 percent, in amounts limited only by the value of Treasury securities held outright in the System Open Market Account that are available for such operations and by a per-counterparty limit of $\$ 30$ billion per day. Federal Reserve issues FOMC statement. March 23, 2020. 
prised in the deepening recession spiral, ends up penalizing the real economy and the productive and commercial activities. While the liquidity resources made available to the Central banks are largely diverted to the market financial sector, so becoming the cause or at least the additional cause of the speculation-financial crisis paradigm. The natural operation core, aimed at hitting and reducing the accumulation of wealth and incomes at the top of social structure, is largely eluded. In this way, the launch of a new speculation-crisis paradigm may be allowed, contrasting the objectives of monetary policy which-through a more balanced transmission inside the hearth of the economy-aims to minimize the damage caused by the crisis on the economy, to facilitate the return to a normal condition.

The condition allowing to elude the natural mechanism reducing the great disparities in the wealth distribution, obviously lies in the capability of the rich part of the society to stay and wait that the troubles caused by the financial crisis would calm down, to resume then the normal management. On the other hand, the availability of low-cost potential credit during the financial crisis obviously offers the possibility of limiting the damage due to the collapse of values and assets (Figure 2).

Inevitable at this point that the same mechanism leading to recurring speculative waves in the 2000s tends to perpetuate, with the result that the profiles

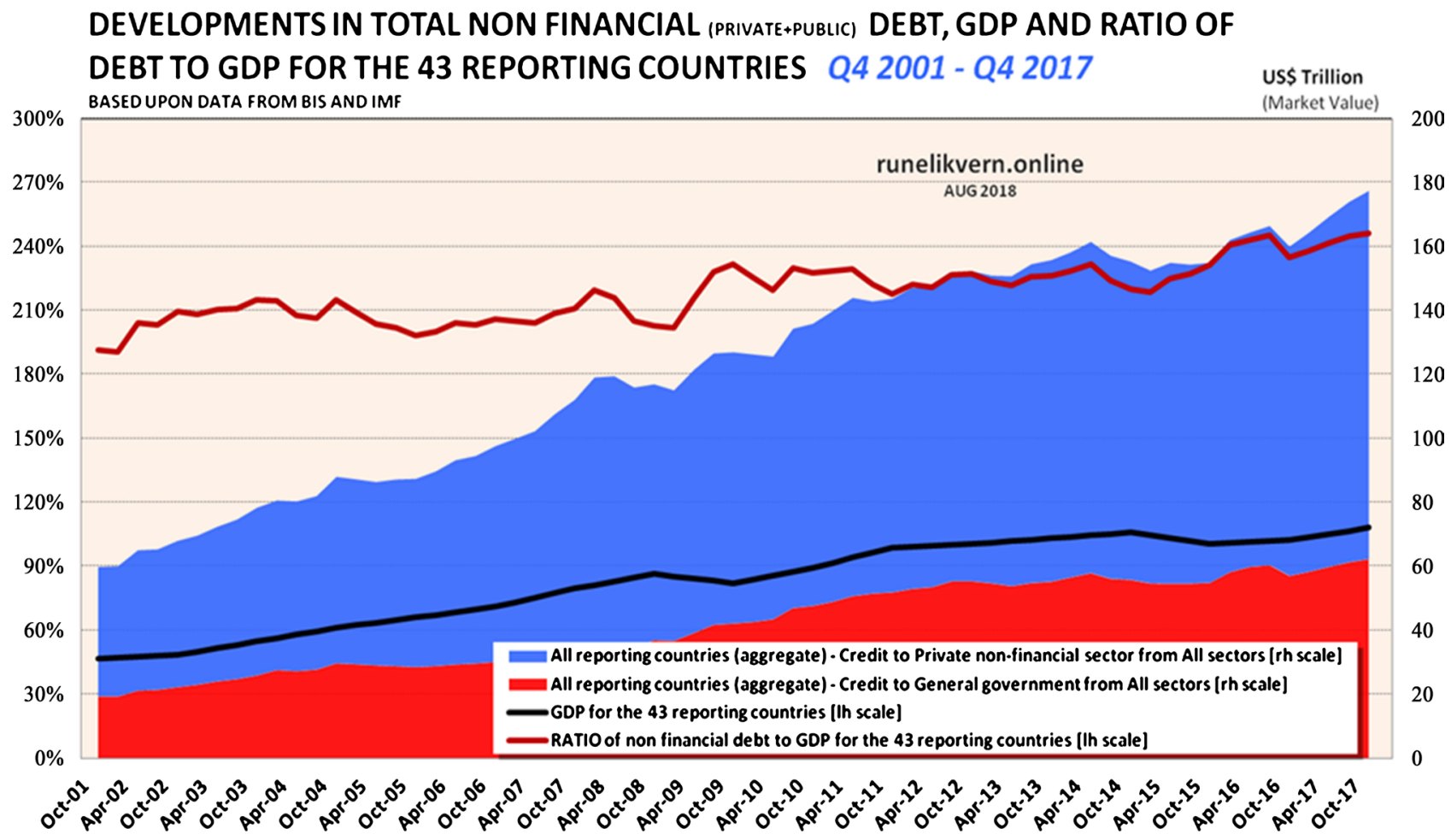

The stacked areas show development in total non-financial [private and public] credit/debt for the 43 economies with data from BIS from Q4 2001 to Q4 2017. The black line (rh scale) shows development in GDP for the 43 with data from IMF for the same period. The upper red line (lh scale) shows development in the non-financial debt to GDP ratio for the 43. Source: https://runelikvern.online/2018/08/21/the-price-of-oil/.

Figure 2. Developments in total and private debt in \% GDP for some big countries. 
assumed by the values in the stock exchanges also tend to follow a sinusoidal trend. There is then a sequence of waves, with a tendency to increase values, which therefore reach new highs, inevitably followed by a deep and rapid fall.

Now apart from the substantial role that the capital plays in the economic management, the problem arises when a constant and continuous trend is created towards the wealth and income centralization to the detriment of majority of the community. A scenario globally spread starting from the great crisis of 2008, when in the western countries the recovery takes strength and with it the great energy that have pushed up to maximum the Stock Exchange value, starting from the USA and China, until at eve of pandemic.

A condition globally extended that may be considered the clear symptom of a heeling of the economy from the equilibrium path. And, according to the sustainability economy, the source of the engine starts the speculation-crisis paradigm. A paradigm that seems to be somewhat facilitated by the choice to provide the unstable economy with ample liquidity. This instability of systems is manifested to the community through the message of the deflation tendency.

Deflation is not an evil, it is instead the symptom of an evil: the instability. The chronic instability treatment is the real challenge we have, in order to avoid a new sequence of the speculation-crisis paradigm in a future series of concurrent events. Now there is no doubt that the treatment with endless liquidity at costs near to zero, responds to real needs. However, that kind of cure largely responds and satisfies the demands of the financial market, which can push-beyond a reasonable growth-the value of shares and assets towards an unnatural sequence proper to speculation (Cossiga, December 2019).

In short, the system seems to have entered a sort of continuous re-edition of the perverse speculation mechanism. It is opposed to this. According to the sustainability rule, the natural mechanism does not tolerate the endless rise of the financial shadow over the economy. And certainly not because of antipathy problems towards the emerging part of society. But because, in terms of sustainability, the core of the relationship between humanity and nature, which is our protective nest, remains centered on the economy. Therefore, the finance must or should only perform a substitute task to encourage the harmonious growth of economic systems. Let us never forget that the relationship between nature and humanity is intended to favor the resource conservation for future generations and at the same time to favor the science, which is generally aimed at the study of natural world.

Ergo everything must move like a good catalyst for the economy's course over time. The concentration over time of income and wealth is openly in contrast to the basic objective, that is to promote the growth of a compatible economy.

We should consider, however, that the growth beyond reasonable values of share prices and assets has a limited influence on the fate of the economy. The advantage of shareholders and speculators, moreover, it is only adding uncertainties to the real economy and the wealth effect given to the owners just be- 
comes a limited part of new offer. In addition, the damage caused by high values, incompatible with the real economy state, would erect barriers against a profitable rotation in the possession of equity values and assets. In this way, the rigidity of properties in the stock market could reduce that tension favoring the success of companies and related production activities. Instead, it is increasingly feeding the interest in a merely financial growth of values, which is the engine of all speculative processes.

These problems do not escape the attention of Central banks, which continue to report the importance that the transmission of monetary policy should be smooth, that is the liquidity injected into the market should benefit the economy and not be attracted to the mere market speculation. ${ }^{5}$ However, reality appears different because it does not seem enough that liquidity is available at a near zero cost, potentially without limits, because the liquidity availability for the economy remains entrusted to the market moods.

\subsection{The Inequality Tendency of Wealth and Income Concentration and the Role of Public Spending}

The problem is therefore the tendency to concentrate wealth in a sector of the community, to the detriment of the remaining part. As we have seen, the potential sinusoidal chain imposed to financial market by the natural correction becomes ineffective in solving at least partially the issue of wealth distribution. The correction mechanism based on the speculation-crisis paradigm is changing things at the top of social scale with the collapse of values of assets, but the effect of cutting values is just a pause in the upward projection of wealth. At the turnaround of the crisis, the dance begins again, dragging the value of shares and other involved assets: and the value promises to reach new highs. A new roundabout in turn leads upwards the curve of wealth and incomes.

It is quite clear that the game is perpetuated with the avoidance of the natural correction mechanism. The economy remains unstable, while the creeping trend towards recession persists. All this means a favorable condition for the financial market, which postulates the unceasing demand for new liquidity, which in part is the vehicle feeding the growth beyond the fair level of the equity values. It

\footnotetext{
${ }^{5}$ The Governing Council was unanimous in its analysis that in addition to the measures it decided on 12 March 2020, the ECB will continue to monitor closely the consequences for the economy of the spreading coronavirus and that the ECB stands ready to adjust all of its measures, as appropriate, should this be needed to safeguard liquidity conditions in the banking system and to ensure the smooth transmission of its monetary policy in all jurisdictions. ECB statement-March 18, 2020.

The Federal Open Market Committee is taking further actions to support the flow of credit to households and businesses by addressing strains in the markets for Treasury securities and agency mortgage-backed securities. The Federal Reserve will continue to purchase Treasury securities and agency mortgage-backed securities in the amounts needed to support smooth market functioning and effective transmission of monetary policy to broader financial conditions. The Committee will include purchases of agency commercial mortgage-backed securities in its agency mortgage-backed security purchases. In addition, the Open Market Desk will continue to offer large-scale overnight and term repurchase agreement operations. The Committee will continue to closely monitor market conditions and will assess the appropriate pace of its securities purchases at future meetings. Federal Reserve issues FOMC statement March 23, 2020.
} 
could be thought that the improper leaven dragging the stock market could be a blessing for the economy.

We can believe instead it has zero effects on the real ground of the economy. The bubble developing inside the financial market is essentially created by the instability of the development path outside the compatibility line with nature. Once the instability has become somewhat structural, we can think that a sort of dichotomy would occur within the market, between the real economy and the financial market, which expands thus creating the speculative bubble.

The economy remains weak and shows the deflationary symptoms. With few or no connections to the real economy, the financial market inflates its values thus creating a virtual wealth and a wealth effect that will be dissolved when the speculative bubble breaks. At this juncture, the real economy has no advantage from the developing speculative process. While is suffering, instead, from a deep backflow when the burst of the speculative bubble makes disappear or abruptly reduce the availability of credit for companies dealing with the lack of liquidity.

As tension increases on the share values, rising beyond the proper level, the finance loses its function of basic pillar for the economy and becomes a sort of "spare wheel", which is useless during the formation phase of speculation. But it becomes extremely harmful when the breaking point is touched, thus destroying the virtual wealth created by the irrational excitement.

We must consider that the natural correction procedure goes beyond the collapse of the values created by speculation. We said that the liquidity profusion on the market cannot easily reach the companies facing the sudden change in the economic scenario. Therefore, there is an increase of firms in difficulty or succumbing for the chronic lack of liquidity. On the level we are analyzing, that is the income and wealth distribution, the companies in crisis are increasing and consequently is rising the wave of layoffs. On a social level, therefore, poverty increases while the income of popular classes decreases, together with the dissolution of virtual wealth created by the irrational speculation.

In these difficult circumstances, the fiscal policy is called to support the economy, with interventions that in the 2008-2010 financial crisis assumed abnormal dimensions, dragging the public debt up to 20 - 30 points in terms of GDP (Figure 3). What significance can we give to these ultra-Keynesian interventions to support the economy and the community income?

Let's now leave aside the considerations relating to the legacy for the future left by the use of public debt for exceptional interventions. At this point, in fact, we are more interested in understanding the impact of public spending on the issue of wealth and income distribution. An initial analysis shows that public spending is a tool for wealth redistribution, even without interventions of capital taxes. The recapitalization of companies in crisis, safeguards jobs and the business continuation. The public intervention to finance infrastructural investments, over time creates jobs and a general occupational benefit. The social 


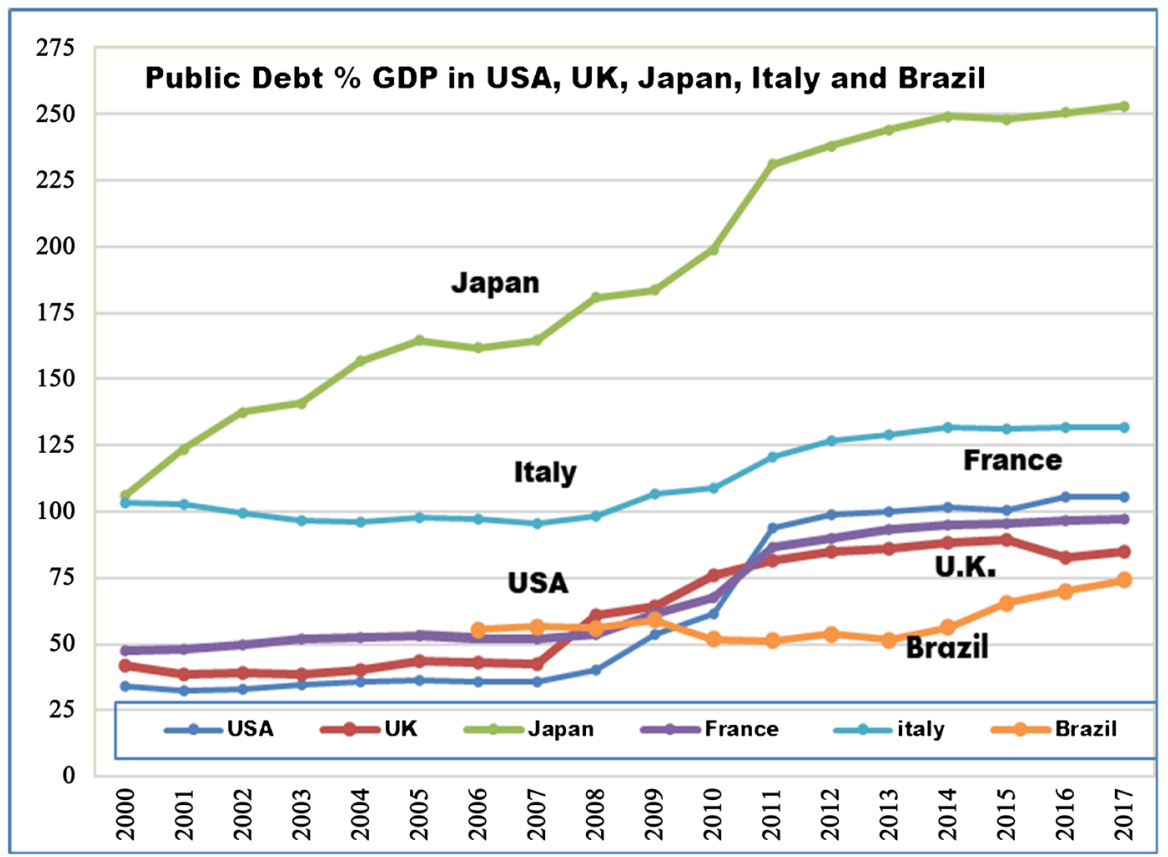

Source-Elaboration on OECD data.

Figure 3. Public debt in percentage of GDP in USA, UK, Japan, Italy, Brazil.

spending to support the income of families affected by the crisis, reduces poverty and social alienation. In general, therefore, public spending in deficit acts with a function of wealth redistribution, thus mitigating the huge social gap that the crisis could further widen.

As saying that the financial crisis operates on a double way to better reconcile the issue of wealth distribution and especially of income equality. Within the high part of society, the crisis makes a partial cutting of wealth, mostly for what we called virtual because created by the speculation, which is swept away by the bubble breaking. On the other hand, the fall for community incomes, due to the loss of jobs, at least partially contrasted by the fiscal policy, which takes the task of distributing to the community that wealth lost at the top level of society. It could be said that the trouble crossing the economic scenario is a natural corrective storm. Like a powerful wind, it is shifting much of the virtual or non-virtual wealth erased by the bubble burst to the rest of community in the form of additional or solidarity incomes.

It should be added that such an option, experimented without parsimony by many states with the massive recourse to public deficit spending, is made possible and feasible provided that Central banks would place enormous liquidity on the market. Reopening the liquidity channels is in fact the prerequisite for public finance to obtain the necessary savings to revitalize the languishing market.

Therefore, the natural correction, which tends irrevocably to keep the economy on a side acceptable for compatibility and balance with the nature, shows a strong and effective action strategy. In the assumption that the speculative ruptures fragmenting the scenario of the global economy can be an effective defense 
against the perversion of an unnatural centralization of resources within a caste of privileged people.

The problem thus is the recharging of the engine that feeds the formation of speculative bubbles and, with them, the new mountain of wealth moving towards the highest part of the community. Specifically, we can certainly admit that there is a wealth and income distribution giving benefits to social categories that actually change over time: from the nobility without any known work to the "creatives" of the technological era. This is an accepted social relationship because, when remaining within the social admission limits, it can be and is functional and facilitates the smooth process of economic compatible development. The bad worm we are talking about, instead, goes far beyond the limits of social acceptance, for the simple reason that the centralization of incomes means the reduction of resources for the remaining large part of community members.

The further issue is that once the unstable economic system has taken the path leading to the formation of the saprophyte "spare wheel" of the virtual wealth creation, a perverse circuit is thus created. Essentially, is reproduced the actual repetition over time of the charge and disintegration phases of virtual wealth, that is created by speculation and which will be swept away by the financial crisis. An evil boil that, once exploded, will affect the area of disadvantaged and poor people.

The dark pillar on which the construction of the virtual spare wheel rests, is the state of imbalance and reduced compatibility with nature, which imposes the deflation trend. A trend that now affects the entire global economy and which is the prerequisite to postulate a progressive drop in the cost of money and an increasing liquidity. These monetary policy interventions, if they reach and are used by the real economy, are tools that can mitigate the economic fall. Therefore, a coordination of fiscal and monetary policy can represent a solid protection for the economy during the development of the financial crisis.

The negative circuit is recomposed afterwards, when the economy's regression ceases, and a slow economic recovery begins. The unstable economy continues-even in this positive situation-to show a stubborn trend towards deflation, which seems indifferent to the state of the economy now recovering. At this stage, the conditions are created to restart the speculation-crisis paradigm.

\subsection{Fiscal Policy and Monetary Policy Move According to an Interlocking Game during the Crisis}

The deflation that the economy creates for structural reasons, just like the conjuncture, cannot be considered only a menace. The development of a balanced economic system is instead structurally stable and follows a constant slightly rising line. This is the natural condition of a balanced economic system compatible with the surrounding nature. The anomaly of the cycle following a sinusoidal trend, with decreasing recovery phases and decrease phases that are extended over time, is the classic signal that the development path became in- 
compatible with the evolution of nature. Above all in contrast with the irrevocable requirement, all-natural resources should be maintained for the future generations (Cossiga, 2017).

The distressed system sends a message to the community of families, companies and institutions that things are not going well, and that the economy management needs to be adjusted according to its natural vocation. The interpretation given by the community to the natural message of deflation is unequivocal: it is necessary to change the style of economy government. The natural message expressed through the deflation of prices is therefore correctly interpreted.

Instead, the response of the institutions is often equivocal and leaves the door open to the resumption of the speculative acceleration mechanism. In fact, the poor growth of the economy, when deflation is in action, urges the ultra-Keynesian intervention of fiscal policy. In the wrong belief that the evil corroding the economic system is the demand weakness and therefore, the exhausted economic scenario should be supported with deficit public spending. A thesis with no real basis, actually.

The intervention of public finance in the economy takes on its meaning and validity only if the intervention has a social support character. That is, aimed to support the most marginalized classes of the community, to correct, though partially, the social tension produced by the unacceptable inequality in wealth and income distribution. In other words, a correction mechanism moving in harmony with the natural one and with the goal to control, through periodic crises, the mechanism of perverse wealth centralization at the top of social scale.

It could be thought that the economic system, in its tendency towards compatibility with the nature around us, would give a solution to the issue of the distorted wealth distribution. However, this trend is hampered by the phenomenon of the constant creation of virtual wealth that the "spare wheel" of finance is continuously producing, during the loading phase of the speculative push.

As noted above, the economy has the strength to grow without any particular help. The only condition is that the development path would not contrast the natural evolution but will remain in the wake of the balanced and compatible growth path. In this case, it is avoided the cyclical alteration in the economy, which would start the periodic recession to curb the abnormal growth and thus to bring again the economy on a steady and gradually rising development path.

According to this approach, the public spending to give breath to businesses can be part of initiatives consistent with the direction of natural correction. In fact, the provision to companies of liquidity with a state guarantee, adopted by many countries struggling with the activity interruption caused by the coronavirus, can have the same meaning. To allow the salary payment along the entire chain of production phases, which if interrupted would have dramatic effects in social terms, assumes the same meaning from the point of view of wealth distribution. Thus, allowing the most vulnerable part of society to maintain an ac- 
ceptable standard of living during the crisis. ${ }^{6}$

We can say the same for interventions in large public infrastructures, at least in part financed by the public intervention, which produces a chain of new jobs. Although with long times, compared to the needs for a prompt action during the financial crisis or during the crisis produced by the new worldwide pandemic.

According to this point of view, ultra-Keynesian public intervention during the acute phase of a crisis moves in the direction of natural correction. In fact, it moves by widening the intervention sphere to support the incomes of the working community. As if the wealth cuts produced ex abrupto by the wave of unexpected recession, were not dispersed but channeled to restore some income to that part of the disadvantaged community facing the bad winds of the economic crisis.

From what has been said so far it seems that, during the unexpected crisis of a sudden recession, events would move in the sense of creating the conditions for a more equitable distribution of wealth and income, despite the general decreasing of wealth. In this case, the drastic reduction suffered by the value of shares and other financial assets should not add any further damage to the real economy. The collapse of these values goes parallel to the implosion of economic growth. But once again the two entities have a relative autonomy.

Nevertheless, the ultra-Keynesian intervention of fiscal policy revitalizes the economic circuit, thus avoiding its fall. A support that is reflected in the strength of the economic system and is also transmitted to the financial mechanism, which receives a boost that also revaluates the depressed values of the shares and other financial assets. As saying that now the finance becomes a saprophyte of the economy and not vice versa.

A favorable exchange between finance and real economy is not reflected instead in recent experience. In the 2000s, the economic growth in the EU has been weak, particularly in the countries of the Mediterranean area. At least two major speculative episodes with related financial crises occurred in the same period, at the beginning and end of the first decade. During the bubble formation

${ }^{6}$ The Kurzarbeit german model—this term is more or less meaning "reduced working hours". It's a scheme of public subsidies which can be activated by those companies severely hit by the crisis. These subsidies can be requested if the $10 \%$ of a company's workforce is forced to a drastic reduction in working hours or even to stay home according to various forms of leave. Previous limit was the $30 \%$ of employees. The provision of $60 \%$ of the last pre-crisis salary will be granted by the Federal Labor Office, the same institution granting subsidies and unemployment benefits according to the guidelines set by the Hartz reform.

To this model were clearly inspired some Nordic countries. Sweden, in fact, in the framework of an overall reform package with tax incentives corresponding to $6 \%$ of GDP-in relative terms one of the most important in Europe-presented a similar project even more generous, paying to the employees of a company the $90 \%$ of their salaries, when forced to stay home or to have a strong working hours reduction. The program started on March 16th and will continue throughout 2020.

In UK, through the Coronavirus Job Retention Scheme the State will cover the wage costs of companies which, otherwise, would be forced to lay off their employees. The rule is that in this period of severe crisis, the employees will remain formally under contract. Salaries will be paid by grants, that is non-repayable loans which will cover $80 \%$ of salaries up to a maximum of about 4000 euros per month. Attilio Geroni-Sole 24 ore, $1^{\circ}$ aprile 2020. Fascicolo 24. 
phase in the second half of 2000, then erupted in 2008-2010, the charge of the speculative process has grown thus dragging the stock exchanges and the property values into an irrational growth. The underlying liquidity and the peculiar hypnotic abandonment of a right risk assessment, gave strength to the boom which cannot be otherwise explainable considering the normal caution of families, companies and institutions. ${ }^{7}$ (Geithner, 2014)

The loss of normal caution of operators can only be explained by the cyclical nature of the economic situation and by the natural correction tool of economic systems development path. Basically, it can be assumed that at the level of financial activity, an autonomous economic cycle is self-powered, parallel and independent, which nevertheless has a greater cadence and tension from that of the real economy. The financial cycle therefore seems to come out when the economy suffers from the deflation symptoms, while the economic growth is weak, and even the conjuncture cycle tends to flatten.

With this situation, the natural correction works through a periodic recession of the economy. Nevertheless, as suddenly appears on the economic scenario the deflation and the weak cycle, the natural correction can start from the deviation of the abnormal financial cycle, which is periodically causing severe troubles to the real economy, thus causing a strong fall worsening.

At this point, the attention turns to the bubble formation phase, which-as already mentioned-is not a function of the economy. Not even in the eruptive phase of speculation, which shows to have a completely autonomous development, separate from the motion of the real economy. As saying that its reasons for development cannot be found inside the fermentation of development which is weak or slowed down. Instead, it finds its stimulus in the underlying tendency to centralize and increase wealth at the top of social scale.

This is the engine feeding the saprophytic cycle of speculative finance through the economic cycle. Only if we were able to stop the virtual growth of wealth, aimed to rebuild and multiply unreasonably the substances of the wealthy class, "At the origins of the 2008 financial crisis there was (and still is) a strong imbalance, typical of our
day, between the world of finance and the real economy of the world, that which is based on goods
and services. In a single day the value generated by financial exchanges was about 60 times higher
than the value generated by the trade of real goods in a year. And in 2006 , a year before the start of
the great crisis, $40 \%$ of the profits in the US market came from financial activities: in short, the
money in circulation had (and still has) a very high value compared to the real and own goods in
circulation around the world. This trend was not new, but a series of reforms to the US financial
system set in the 1990 s made it stronger than ever. In the 1990 s, the United States decided to reduce
the rules of finance to make the system freer and more efficient, abolishing some regulatory and
supervisory authorities dating back to the 1930 s. Financial exchanges were liberalized through the
Gramm-Leach-Bliley act. The law introduced bank holding companies, real "financial giants" capa-
ble of bringing together various banks and insurance companies, to offer any type of financial ser-
vice. Before then, only "commercial" banks had been able to collect and keep the accounts of
American families, while more risky investments had to be made by another type of bank: invest-
ment banks. Two types of banks could not merge into a holding company. The main consequence
of the modernization law of 1999 was that household savings began to be used for rather risky fi-
nancial transactions: banks could borrow excessively and at the same time lend money without suf-
ficient guarantees to get it back. 
we could defeat the continuous re-edition of the speculative finance secondary cycle.

Now there is no doubt that we can exclude an even partial participation of the real economy to the speculative game, as it is evident from the limited relationship between the two phenomena. Even if the economic weakness seems to be the underlying motivation that makes the speculation strength emerge and prevail. I mean that the economic weakness after the 2008-2010 financial crisis was accompanied by the trend towards price deflation. Assuming that this weakness can be treated with the classic formulas of deficit public expenditure, the fiscal support policy remains active. But the expansion of public spending puts some growing limits to new neo-Keynesian packages.

Monetary policy thus is called to perform a cooperative function to help the economic management. By purchasing public and private securities on the market to support their value and ensure the creditworthiness of both the public sector and the medium-large companies. By providing banks with new liquidity, to give resources to companies, which are hungry for liquidity in a market without resilience guarantees.

As saying that during the financial crisis caused by the speculation-crisis paradigm, the modulation of fiscal and monetary policy interventions moves according to a sort of interlocking game. Therefore, the liquidity created without limits by the Central banks is a necessary tool to make the public support and investment interventions able to deploy their effects on the market. All right, then? Probably yes, at least as long as the scenario is that of the financial crisis and the recession in progress.

However, when we face the slow recovery of the economy, maybe faster than expected due to the support of joint policies, the problem remains that we are not witnessing a strong recovery in the economy, which instead is recovering with some weaknesses. Furthermore, it remains evident the stubborn tendency of economic system to deflation. An apparent anomaly, especially because it doesn't follow the examples of the eighties, marked by severe recessions (at the time of President Reagan) followed by a strong recovery. We cannot make comparisons, anyway. We are in deflation times, not treatable by starting the ride of a recurring speculation. Quite the opposite, indeed!

\subsection{Is the Financial Market Always Powering the Economy?}

Deflation is a message to the community to take note that the economy is unstable and follows a development path not compatible with the environment evolution. Currently, with the deflation globally spread, we must believe that the ride mechanism of recurring speculations, which in the same way is globally spreading, has a unique and general meaning. In other words, we can believe that the primary reason for the instability escalation and spread, can be measured by the parallel phenomenon of wealth concentration at the state level, starting right from the USA and China. 
As saying that the process guiding the wealth and income concentration may be the engine or one of the engines of the speculation-crisis paradigm that is globally advancing. The new wealth accumulated during the global economic recovery phases, then takes a temporary virtual value. It will therefore be subject to demolition, in order to avoid that phenomenon could continue, to the detriment of community's majority and with incalculable damage on the economic and social level.

At this point, we should try to understand how the speculation ride could finally be stopped or rather how to end the apparently endless mechanism of wealth concentration. As already mentioned, the problem could mature due to the deflation tendency, which in practice makes somewhat perennial the continuous contribution of fiscal and monetary policies. The objections come from their continuity, while it would be expected that at the end of the financial crisis outbreak it would be possible to finally enjoy an economic calm and a pause in the interventions.

It seems to understand that this persistence of economic incentives is somehow forced, or apparently so, by the persistent tendency to deflation. In fact, it is quite usual to believe that the conjuncture tightness can remove the specter of lurking deflation. Therefore, Central banks are focusing on the recovery of the economic cycle to predict a parallel rising of inflation. Now it is clear that the recovery of the economy produces a positive inflation, which is obviously added to the negative inflation produced by the unstable system. In short, we are facing a sort of arithmetic effect and not an exit from the deflation orbit (Cossiga, June 2018).

The abundant liquidity and the drop of money cost are also involved to contain the deflation strength, but also in this case the positive floating of the inflation rate is linked to the fate of the conjuncture cycle, which can benefit from the greater liquidity in circulation.

Now, these effects somehow "optical" about the improving value of inflation are however the justification for the extension of coordinated policies support. And it is here, indeed, that could be hidden the fuel powering and feeding to speculative strength. It is certainly not difficult to admit that liquidity excess and money low cost near to zero could be the speculation charge, when the conjuncture is showing the recovery signal. On the other hand, we should consider that this economic condition (weak recovery and deflation tendency) has been interpreted from the point of view of the current contingencies.

Trump's America thus did shake up the economy by cutting taxes, especially for the benefit of the wealthy people, with an additional burden for the public budget. As can be seen in the graph below and from the arguments covered by notes, the tax cut in the USA has again moved things in favor of the wealthy part of community and at the same time has been the driving force behind the run of the main Stock exchanges in America.

All this has somewhat accentuated the propensity in America, and indirectly 
at a global level, to recharge speculation and has somehow worsened the problems troubling the economy across the Atlantic. With various reasons and objectives, the majority of the most industrialized countries resorted to increased debt to support an economy that doesn't run, while in contrast the values of Stock exchanges and other financial assets continued to run (Figure 4).

On the other hand, the thesis supported also by Central banks that the economic situation can keep nominal prices to stay high, is technically the leaven that allows the speculation phenomenon to continue in its saprophytic progression, despite the economy almost frozen. Even in Trump's America the push given to the economy by the tax cut during the two-year period 2018-2019 must be considered just a cycle advance, if not a virtual process which-as we are now witnessing-is a fragile construction, abruptly demolished by the coronavirus crisis.

Now it does not seem so impossible that the ashes of the speculation fire are ready to rekindle when the economic situation stops falling and the recovery peeps out. Then, the market section which suffered the greatest damage, that is the financial wealth powered by the Stock exchange values, postulates the need to maintain the great liquidity that was justified by the crisis and that now should be gradually reabsorbed. Nevertheless, this does not happen in the usual hope that the liquidity feeding the financial market could be also an engine for the revitalization of the weak economy.

Once again, we make the mistake of assuming that anyway he financial market is always an engine for the economy and that its rise, even beyond the fair values to be considered for business companies, would represent always a supporting factor

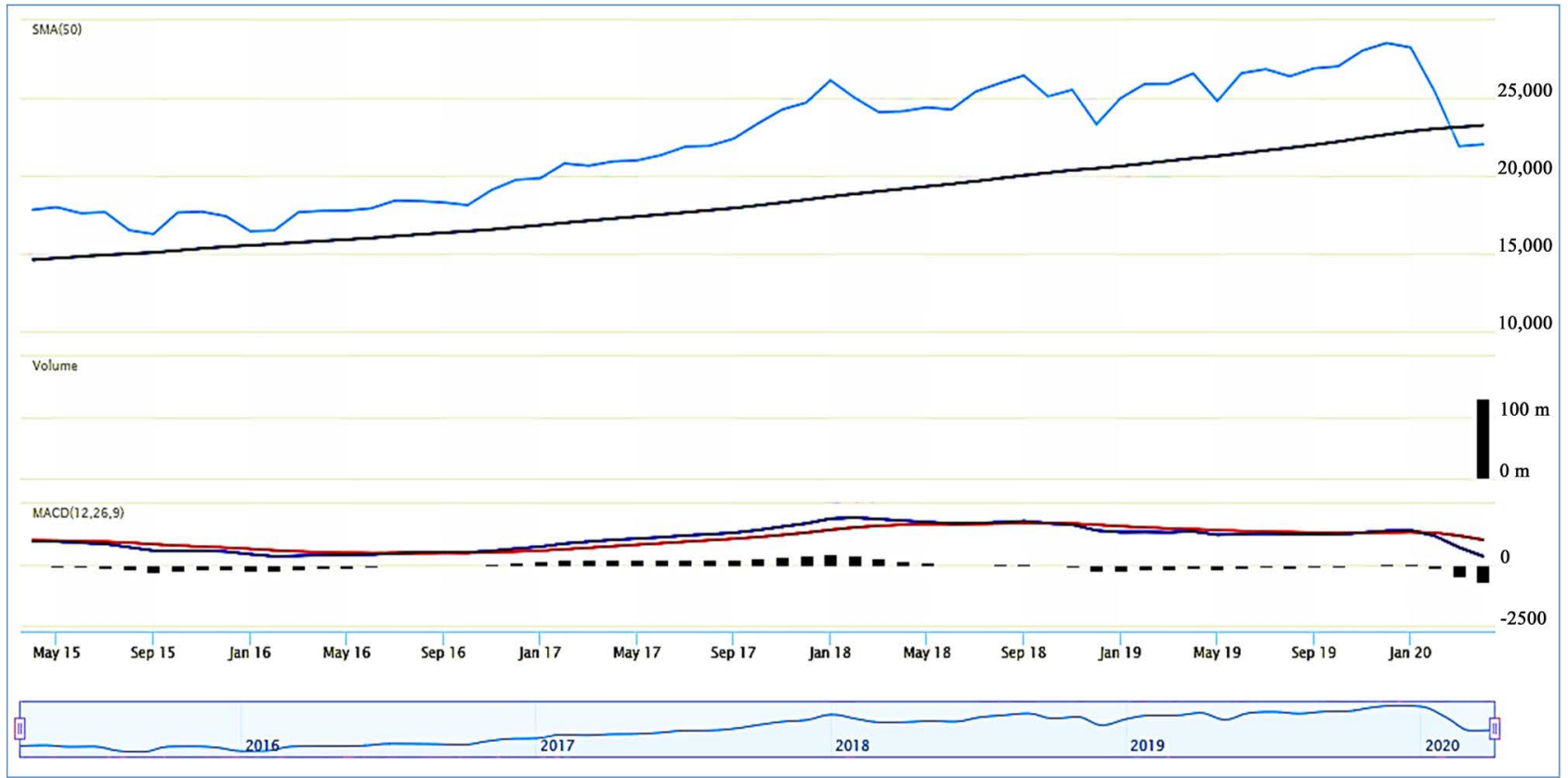

Source: Financial information on Market Watch website.

Figure 4. Trend of Dow Jones Industrial Average from May 2015 to June 2020. 
for the real economy. But this is not true, at least partially. Because if there is no doubt about the profitable relationship between finance and economics when the economy is supported by the capital, the same cannot be said when the relationship is broken. While the economy is cooled under the blows of prices tending to deflation, the irrational excitement of the financial markets instead becomes a poison for the real economy and is also threatening the employment (Roubini \& Mihm, 2011).

Basically, the speculation-recurring crisis paradigm is to be considered a natural model to correct the illogical and unequal wealth distribution, which tends anyway to be concentrated. In other words, the natural model poses an insurmountable limit to the process of resource subtraction: resources concentrated, in fact, in the upper part of the social hierarchy. All this trouble must be considered a consequence of the economic systems' instability, due to the breakdown of the relationship with the nature around us.

It is therefore necessary to interrupt this unreasonable and destructive cycle of the financial market as a sort of anomalous "spare wheel", by limiting or controlling the source feeding its perverse cycle. It is now clear that the recharge mechanism starts when the feeling prevails that the crisis is overcome, though with serious damage. It is therefore evident that the iconic hope that economy and finance would follow a common path of recovery, will push liquidity to be channeled mainly in the financial sector of the economy, on the assumption that it will be the driving force for the real economy. Moreover, the rapidly recovering trend in the financial markets pushes the credit to target even this sector, which seems apparently less risky.

At this point, the fiscal policy which remains permissive to give strength to the economy, and the monetary policy which seems to be dominated by the market always hungry for new liquidity, come into play. Now, if we exclude the equation that feeding one of them means empowering the economy, it is clear that this engine supplying the speculative bubble must be turned off. Or rather, must be checked to ensure that the transmission of monetary policy would support the economy directly and not in mediated form through the unrelated development of financial markets.

\section{Result}

\subsection{The Defensive Reaction of the Financial Markets}

Returning to the coronavirus issue and the abnormal impact affecting the economy for the lockdown, it can be observed that a sudden downturn of the markets was expected, as a consequence of the loading of speculation spiral, particularly in the USA and China. Aside from the recessionary wave extent created in all countries by the blockage of activities (the lockdown), we could wonder if a new 2008-2010 economic earthquake is coming, or it's just a sudden unexpected interruption and therefore difficult to predict.

In the first case it might be assumed that the coronavirus event has substan- 
tially accelerated or even worsened the consequences for the breaking of the speculative bubble in progress. Otherwise, the breaking of the economy pace will only partially influence the speculation path. Meaning that the strong support globally provided to the economy, basically should also become a shield against the losses in the financial markets, which could therefore see a recovery hint from the low levels touched. So that its function of excess demolition on the front of accumulated wealth is at least partially eluded. ${ }^{8}$

This is to say that the speculation strength, understood as a tendency to accumulate wealth, is difficult to be put aside. Even when gone off the deep end, the leaven of this irrational energy can be found in the widespread feeling that the finance strength will be the boost for real economy. This is not only untrue but can also bring recurrent serious crises that cancel or reduce large resources of community (Figure 5).

Even the recent experience about the strength of the irrational push, can convince that the expected recovery of the economic situation is the real starting point for speculation recharging. Obviously, this high pressure on financial assets could be to the detriment of the real economy, through subtraction of capital and credit capacity for investment, also caused by the liquidity absorbed to feed a negative leaven that drives the speculation circuit.

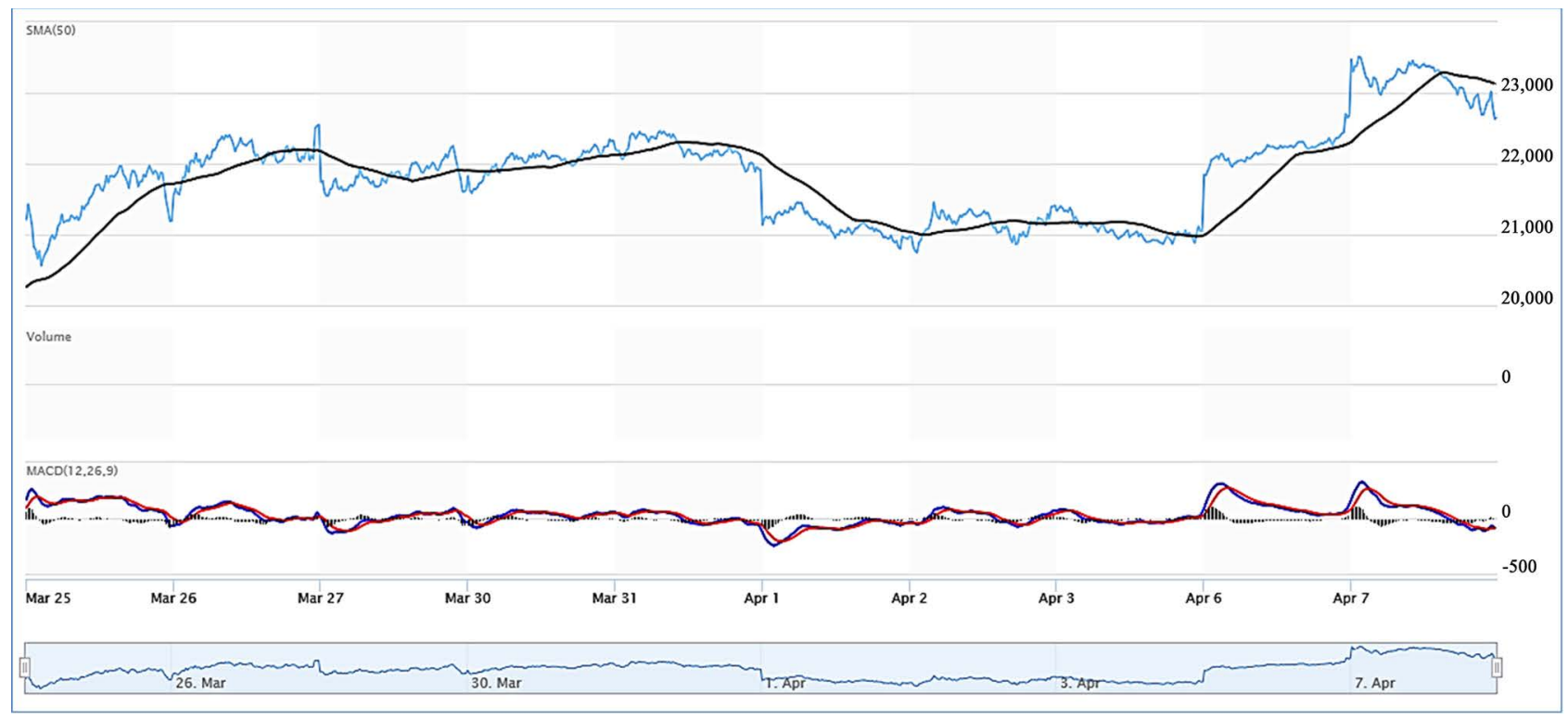

Source: Financial information on Market Watch website.

Figure 5. Trend of Dow Jones Industrial Average from 25 March to 6 April 2020.

${ }^{8}$ From the lows reached between 12 and 23 March, depending on the various Stock exchange lists, there were in fact double-digit rebounds for everyone. Analyzing the data for the first week of April, some Stock exchanges, such as those in Paris or Moscow or Brazil, even entered that phase called "Bull": that is a recovery from lows of more than $20 \%$. Nevertheless also those under this level aren't so far from this result: Wall Street, just to say, from minimum to maximum recovered $17.6 \%$. From the lows of March 23, the global equity index Msci World on April 15 recovered 23\% of its value. The rebound of Stock exchanges was accompanied by a resumption of subscriptions of equity funds, following the severe capital loss recorded in March during the Market sell-off. 
It is now clear that during the critical phase of the financial crisis, the value of the assets and securities also falls far below the real value of the companies and below the values they represent. Therefore, not only does the "spare wheel" of alienated finance bring with it a value excess, compared to the fair market measure, which is unfavorable for the economy as we said, but it's also putting a wall per financial capital defense. In fact, the downside is no less negative. The drop well below the fair level of market values and financial assets is reversed as a weakness indicator for the real economy which, also for this reason, is even more affected by the lack of liquidity and by difficulties in the outlook forecasting.

So, the goal is clear: to avoid that the anomalous and speculative cycle of finance would be fueled, thus producing its effect by affecting the economy both in the phase of sharp decline and in the irrational phase. Equally obvious is that the emergency is driven by liquidity excess on the market. Basically, it could be certainly admitted that there must be a concerted cooperation between fiscal and financial policies. In the sense that the almost continuous support offered by the public budget to the business sector and to the most marginalized part of society, somewhat mitigates the pressure of the real economy on credit and finance. But that support can represent a sort of free doorway for a considerable part of the new liquidity let to go towards the financial pole, in the doubtful assumption that it could also be of some help to the community.

A mix that seems harmless but instead it is decisive for the recovery of the real economic cycle. It can create the de facto conditions to get back the speculation game and above all to restore the irresistible tendency of the owners of great wealth to recover and increase their funds. We must believe that this trend is the result of instability and that the reloaded speculation is just a defense mechanism that the economic system devised in order to avoid the strangling of markets caused by the limitless concentration of income and wealth.

In order to defeat the reiteration of a speculation snake continuously knotted, a limit must be established, based on historical experience, to the Price/Earning standard value ${ }^{9}$ and to the fair value ${ }^{10}$ when we're making reference to a given financial market. It is a question of preventing the financial market evaluation, expressed by the Stock market values, from exceeding the historical value by a certain delta.

\footnotetext{
${ }^{9}$ The P/E average value referring to all the shares listed on the US market during the period 1981-1996 was 17.5.

${ }^{10}$ Adopted by the International Accounting Standards Board on May 12, 2011, IFRS 13 provides guidance for how to perform fair value measurement under IFRS and became effective on January $1,2013$.

The guidance is similar to the US GAAP guidance. It defines fair value as "the price that would be received to sell an asset or paid to transfer a liability in an orderly transaction between market participants at the measurement date (an exit price). When measuring fair value, an entity uses the assumptions that market participants would use when pricing the asset or the liability under current market conditions, including assumptions about risk." As a result, IFRS 13 requires entities to consider the effects of credit risk when determining a fair value measurement, e.g. by calculating a credit valuation adjustment (CVA) or debit valuation adjustment (DVA) on their derivatives. Paui Barnes-IFRS 13 Fair Value Measurement. What does this mean for valuation?
} 
At this point, some penalties could be imposed on the holders of the securities of the main companies on the Stock market. This will be done in the terms and ways that should be studied with the aim of triggering a process that will accelerate the sale of securities, in order to help moderate the irrational development. A similar action could be taken on all the assets that, following a speculative logic, are showing a tension to increase the value that exceeds by a quid to be determined, the historical average value of those assets (Barnes, 2011).

In any case, it is precisely the strategy of indiscriminate market support that must be impeached, as a potential tool able to create virtual values, which sooner or later will reach a breaking point. A balanced economic system, moving along the stability path, does not need any protection measures because it can grow autonomously according to a linear and slightly rising path. The conjuncture landscape and even more the financial speculative landscape are creations of the instability world. From this point of view, it would not make sense to fight against these creations of the instability because the real problem is to find the way to return to the path of balance with nature. Without having, therefore, the ambition to be able to stifle these natural corrective events, which as such cannot be governed with the classic tools of the economy.

The financial market, therefore, has a basic irrationality, which is coming out by the way in the credit risk assessment; risk that changes if the creditor is public or when he's private and particularly according to the company size. Just a few years ago, the market penalized the Euro-member states of the Mediterranean area, with the simple assessment that the public debt had reached and exceeded $100 \%$ of GDP. Penalization made through the increase in the rates paid by the public sector of these countries to stock up on the market. Thus, the spread between the rate requested by the market from these countries has widened compared to the near zero rate for German loans.

Well, the market lucidity in pursuing public debt can be found in the financial area tension to the wealth concentration. In fact, as we said, public debt is seen as the leading tool to contain social malaise and difficulties of the real economy. Therefore, it is the tool that fights, somewhat successfully, the formation of a mechanism which is concentrating wealth in the high levels of society. This can lead to a distorted assessment made both by those countries penalized by uncontrolled rates and by those awarded as the guardians of financial orthodoxy. As saying that the reward of one part corresponds to the damage for the other party. Therefore, a partisan financial market is strongly contrasting the attempts to limit the constant process of wealth accumulation.

On the other hand, the fact that it may be a not so fair evaluation of the creditors' capability to repay the credit, appears evident also if we observe the lack of attention of the financial market about the debt volumes of companies and individuals, abnormal when compared to the real economy (Figure 6). A judgment that is based-perhaps falsely-on the cheap and abundant liquidity. In this regard, it's sufficient to consider the key interest rates of the main Central banks 


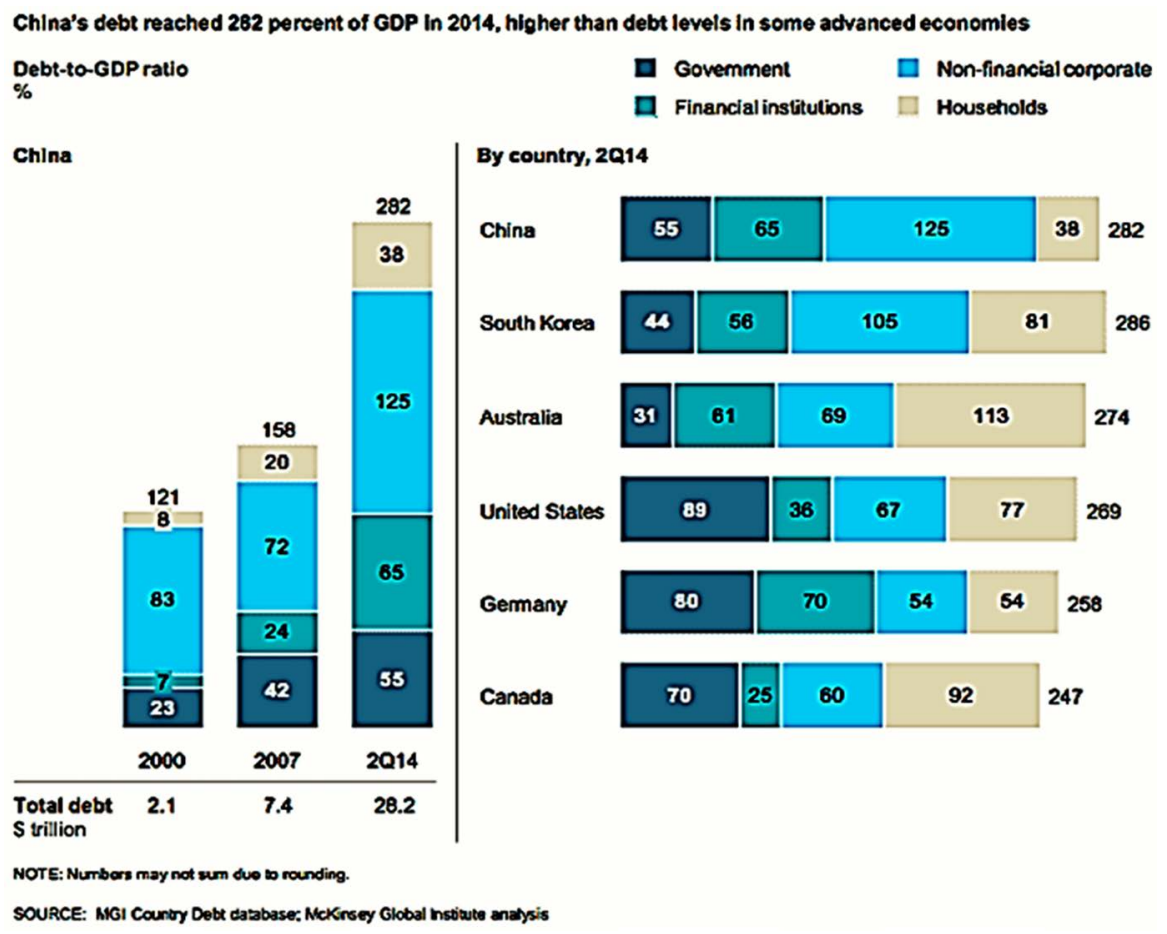

Figure 6. Debt in percentage of GDP for China and for some advanced countries.

during the first decade of 2000 before the financial crisis, as well as the creation of unlimited liquidity through the so-called subprime in the Real Estate sector.

It is quite easy to think now that the different assessment made by the market for the debt of individuals and companies is related to the need for credit as the primary engine concentrating wealth at the top of social scale. The credit addressed to the public sector, somehow escapes the speculation market, and limits the strength of the tireless wheel that loads values unrelated to the real economy. Thus, the market becomes a mirror of this ambivalence and acts, at least during the most intense phase of speculation, as a solicitor favoring one against the other.

\subsection{The Liquidity Stream Feeding the Financial Market Bubble}

At this point, given that the double helix of the economic and financial cycles is a sign of the growing instability of economic systems, to curb and block this dangerous effervescence we must return to the natural path of the evolution compatible with nature. In the meantime, what to do at least to curb the strength involving the financial market in the period of irrational excitement?

Now it is evident the responsibility of the stream growing up to become a great river of cash going towards finance, thus increasing the asset values. Just as hypothesis, it could be assumed that after the long recovery phase from the financial crisis there should be a substantial cooperation between the economy and the finance to revitalize the fate of the real economy. So, it seems questionable an active cooperation between fiscal policy, providing support to companies 
and households, and monetary policy, contributing to make fluid the development of markets through the availability of cheap credit.

As the experience of the 2000s has shown, the succession of speculative returns doesn't offer any defense against the some speculative rise, as if markets had lost not only the risk awareness but also the memory of the unexpected collapses of recent past. This suggests that there is a sort of hidden force gradually pushing over time towards the brink of the inexorable bubble breaking. We cannot explain this anomaly without considering the irrevocable tendency of markets towards the balance and the compatibility with nature. It's a force comparable to the gravity and electromagnetic forces, which can avoid, with some elasticity, the fall of the economic world into an irrevocable natural catastrophe (Bernanke, 2000).

On the other hand, the warnings sent by the economic system to the community for a remedy to the incompatible development degradation, were unsuccessful. It is therefore worth thinking that these intermittent alterations of finance can be classified as a natural mechanism, somehow particular, to catch and correct the core concerns in the economic evolution.

Well, let us now go back to the issue of the engine contributing to form the speculative wave: it seems possible to admit that the finance emphasis occurs when, after a few months or even years, the economic tone remains weak. This is also due to the continuous effect of the deflationary trend now involving the global economy. The attempt to revive the pale fate of the real economy is generally unsuccessful because the weakness of the markets depends on instability and cannot be treated through the ordinary therapies of fiscal policy and convergent financial policy.

The drastic cure to curb the financial values run, seems therefore to pass through a credit drastic narrowing against the financial market. At least when using the higher values created within the financial market to recover the losses suffered due to the fall in values caused by the financial crisis and then to increase the distortion in the wealth distribution. Well, the discrimination between the credit share provided to the real economy and the part feeding speculation is not simple at all, if only for the confusion of roles between managers of productive activities and capital owners going around during the bubble formation.

As saying that an easy tool to better calibrate the credit direction during the formation of the speculative bubble, does not seem to be available. Moreover, a bureaucratic anomaly of controls could arise and, in the end, would damage the real economy, which instead needs to be sustained. In principle, we could think to curb the speculative increase in financial assets by establishing in the meantime a fair market value for the listed goods and companies. This difficult task could consider the average value over time, updated with inflation, and increased by a percentage depending on the change in GDP. The surpluses over the average values calculated in this way, could be subject to a progressive taxa- 
tion, as the prices of a given asset would grow.

The goal would be to encourage the sale of those goods overvalued to avoid taxation, so that the rising sales would have the effect of reducing excess values. I would like to repeat that it is a difficult equation to solve on a social level, due to the strong opposition that would come from the privileged social categories endowed with political conditioning power.

It should also be considered that the attempt to address the credit in order to prefer the real economy, thereby reducing the energy source for the speculation, it might actually be almost ineffective. And this is for the confusion arisen between the managers and owners of the Companies: and particularly the listed Companies. So that the credit activated by companies would in turn be left free to flow towards those assets involved in the speculative run.

Apart from the possibility to solve now the problem created by the speculative cycle that overlaps the economy, it seems important to reduce that flow of cheap liquidity: in any case, that flow should decrease in proportion to the improper development of the financial market in the Stock exchange or in other complementary areas. As already mentioned, to believe that the deflation tendency could be adjusted through monetary policy measures has no consistency. Also, because the core of economy weakness does not lie in the deflation, which is only a symptom and not a reason for malaise.

The absorption of liquidity excess can create disruptions in certain production areas. Disruptions that can be managed by tax policy, which can better act against the lurking speculation. Moreover, it is about eliminating and controlling the financial anomalies that in the short run can re-propose the fearful super-cycle of crazy finance and the social and economic damage that unpredictably unleashes on the real economy.

The basic issue is therefore to interrupt the perverse mechanism that loads the shift of wealth towards the privileged categories, to the detriment of the remaining community. It is socially unacceptable the perspective that the community undergoes a continuous reduction of labor incomes and thus a continuous increase of widespread poverty and then of masses of excluded: all this, in the face of wealth and incomes generally increasing but going in the wrong direction, towards concentration.

So, the challenge is to block or even better to reverse this improper order in the distribution of resources. Experience tells us that the state shows to be defenseless to counteract the wealth centralization movement. We must consider that the use of extraordinary taxation to target wealthy owners beyond a certain value appears unlikely on a political level, due to the contrasting power held by the privileged categories. On the other hand, an extraordinary property tax, although made more acceptable through a documented and widespread information on the reasons that made it necessary, may not have the desired effect. Both because many riches are not liquid and therefore the tax is difficult to be collected and because the real economy would be damaged by the consequent ex- 
traordinary sales.

\section{Conclusion}

Despite these undoubted difficulties, a gradual and reasoned solution to the problem could only be achieved on a voluntary basis. This is not something new, by the way. Because on a voluntary basis, the "philanthropic" phenomenon, still limited and not significant in terms of results, is vital and seems to have the strength necessary to grow. Just think about the charitable foundations with great assets provided by billionaire philanthropists ${ }^{11}$ or about donations having the purpose of interventions to alleviate poverty, to help research and to preserve the artworks.

There is now a real perception at the community level that to concentrate wealth is unethical and unequal, and that we must somehow balance the disproportion increasingly evident between the wealth of a few and the poverty of many. And this should be done at a planetary level. Now, assuming that a taxation policy against large estates and wealth is not yet feasible, we can resort to the wide spreading phenomenon of donations addressed to scientific research or to poverty reduction. According to this profile, though currently only voluntary, we can hypothesize a sort of mixed formula that could convince to convey the distribution of resources towards a more equitable scenario.

Thus, it could be imagined proposing to the great wealth owners a voluntarily transfer of part of their own substances (let us say $5 \%-10 \%$ or more) in the form of money or easily liquidated assets. This transfer would be made with a destination to be specified, among institutions and research centers, as well as for the poverty reduction. A portion of the total amount should go to reduce the public debt. This could be a logical approach to contain the effects produced by the financial crises, which accumulate an increasing debt burden, thus, giving a

\footnotetext{
${ }^{11}$ The Chronicle of Philanthropy, a magazine focused on the world of non-profit companies, has calculated donations from 2000 to today, in addition to the total amount, for the percentage of the benefactor's assets used in charity. Even looking at the percentage in relation to the total assets, Warren Buffett stands out above all with 46 billion dollars, which represent $71 \%$ of his wealth. Bill Gates is on the second step of the podium, with $22 \%$, and Michael Bloomberg on the third with $10 \%$. The big excluded, both from the Forbes and the Chronicle of Philanthropy rankings, is Jeff Bezos, the current richest man in the world. According to CNBC, in fact, the owner of Amazon and the Washington Post has devoted only $0.1 \%$ of his assets to philanthropy. The European Research Network on Philanthropy (ERNOP), an association of researchers specialized in the study of philanthropy, estimates the money that benefactors of the European continent donate to charity in one year at 87.5 billion euros. For more than half, with around 25 and 23 billion a year, are contributing the citizens of the United Kingdom and Germany. For the Germans, the component that companies donate to charity is very strong, 11 billion, the highest in the whole of Europe. Forbes presents an image of the economic significance of philanthropy in Asia and Oceania, through statistics relating to the major benefactors. In China, the first place is occupied by Chen Yidan, co-founder of Tencent, an investment holding company that also holds WeChat, which in 2017 donated over 320 million dollars, mainly intended for educational projects. Another philanthropist is Yao Ming, the famous basketball player, who every year finances sports and recreational activities in the most remote areas of China with $\$ 2.5$ million. Andrew Forrest, an Australian steel entrepreneur, donated over $\$ 300$ million to charity last May, the highest sum ever donated in the former British territory. https://www.startingfinance.com/approfondimenti/miliardari-la-filantropia/.
} 
warning on the character of anomalous center of wealth redistribution entrusted to the spending surpluses in deficit.

The donation could have some advantages although limited: it could be considered to establish that, if the donation would reach a certain amount, the taxation of the year's income will be reduced or even cleared. For donations aimed to finance the restoration of a monument or artworks, there may be a clear trace of the donor who made it possible to do the work. The same kind of dedication could be done for those who intend to allocate part of their assets to scientific research, when important and significant objectives are achieved in the different scientific sectors.

Now, it is unlikely that a propaganda, though well-directed, to encourage spontaneous and voluntary donations would have a wide result, such as to allow a widespread redistribution of resources at the level of each country. Of course, to reach a useful dimension, an initiative of this magnitude should be concerted by all the most important countries and organized all together. The phenomenon of the financial cycle recurrence, staggered and extremely dangerous compared to the cycle of the real economy, has a global character and therefore must be addressed not at the level of individual states but as a whole, according to a necessary general concert.

In order to obtain the progressive dissolution of the formation process of speculative bubbles, the encouraged vocation to voluntary contribution wouldn't probably be enough to start the project of a more equitable distribution of resources. Therefore, a measure should be adopted, even at a global level in concert between the major countries, which would also impose a tax for highest assets (always in the order of $5 \%-10 \%$ or more). This charge would be imposed on the wealth holders beyond a certain level (according to a parameter to be determined) who did not consider to voluntarily pay their share to be transferred. For those who did not join the voluntary payment, obviously would not be available the guarantees granted only to voluntary adhesions regarding the income taxation.

We set out to examine what happens in the global scenario in the post-pandemic, starting with the phenomenon of centralization from wealth, to the social use of public debt as an antidote. We therefore focused on the issue of the probable formation of a secondary wave aroused by the cycle of finance, distinct from that-succubus-of the real economy. Issues and evidence were presented that even the man on the street is able to collect, even if not in an orderly form.

The pandemic may have the effect of postponing, altering, or ruffling the picture, which, however, can then be clarified. The knot remains, however, the centralization of wealth globally or within each community and the consequences that the natural and inevitable process of correcting excesses is destined to produce, if one does not run for cover. One might have doubts about the complex natural pattern that stands behind the coexistence process between humanity and nature. Perhaps it is possible to find an alternative image that may be able to 
justify the insurmountable rule that justifies humanity's past and future presence on the planet.

\section{Conflicts of Interest}

The author declares no conflicts of interest regarding the publication of this paper.

\section{References}

Barnes, P. (2011). IFRS 13 Fair Value Measurement: What Does This Mean for Valuation? New York: Duff \& Phelps.

https://www.duffandphelps.com/insights/publications/valuation/ifrs-13-fair-value-mea surement-what-does-this-mean-for-valuation

Bernanke, B. S. (2000). Essays on the Great Depression. Princeton, NJ: Princeton University Press.

Cossiga, G. A. (2017). Stability and Instability of an Economic System: Considerations. Review of European Studies, 9, 8. https://doi.org/10.5539/res.v9n3p8

Cossiga, G. A. (April 2018). Signals from the World of Economics. The Price Constant and the Democratic Issue. International Journal of Social and Administrative Sciences, 3, 1-21. http://www.aessweb.com/pdf-files/IJSAS-2018-3(1)-1-21.pdf

Cossiga, G. A. (December 2019). The Economy of Sustainability: Some Consequences on the Economic Theory. Theoretical Economics Letters, 9, 3034-3064. https://doi.org/10.4236/tel.2019.98187

Cossiga, G. A. (June 2018). The Search for Inflation on a Constant Basis at 2\%. Social Sciences, 7, 165-181. https://doi.org/10.11648/j.ss.20180704.13

Cossiga, G. A. (May 24, 2019). The Instability of Economic System and the Errors in Economics. Journal of Asian Research, 3, 162. https://doi.org/10.22158/jar.v3n2p162

Geithner, T. F. (May 12th, 2014). Stress Test: Reflections on Financial Crises. New York: Crown Publishing Group.

Krugman, P. R. (2009). The Return of Depression Economics and the Crisis 2008. New York: W.W. Norton \& Company, Inc.

Roubini, N., \& Mihm, S. (2011). Crisis Economics: A Crash Course in the Future of Finance. London: Penguin Books.

Shiller, R. J. (2015). Irrational Exuberance Revised and Expanded third Edition. Princeton, NJ: Princeton University Press. https://doi.org/10.2307/j.ctt1287kz5 